\title{
Mutation in hprt1 Gene or HPRT Deficiency May be a Restricting Progeny of Favipiravir in Covid-19
}

Muhammad Torequl Islam

Department of Pharmacy, Life Science Faculty, Bangabandhu Sheikh Mujibur Rahman Science and Technology University, Gopalganj (Dhaka) - 8100, Bangladesh

DOI: $10.36348 /$ sijtcm.2020.v03i08.001

| Received: 10.09.2020 | Accepted: 18.09.2020 | Published: 24.09 .2020

*Corresponding author: Muhammad Torequl Islam

\section{Abstract}

Favipiravir (FPV), a pyrazine carboxamide derivative (6-fluoro-3-hydroxy-2-pyrazinecarboxamide) is a broad-spectrum anti-viral drug which acts against many species of Arenaviridae, Bunyaviridae, Caliciviridae, Filoviridae, Flaviviridae, Orthomyxoviridae, Paramyxoviridae, Picornaviridae, Rhabdoviridae, Togaviridae groups. According to the WHO, FPV may be a new hope for the treatment severe acute respiratory syndrome coronavirus 2 (SARS-CoV-2) infections and for this it has undergone for a number of clinical trials. However, human hypoxanthine guanine phosphoribosyltransferase (HPRT) is believed to play a key role in its physiological activation process, therefore, the patients having KelleySeegmiller syndrome, Lesch-Nyhan syndrome, myocardial ischemia, hyperuricemia, anemia, and phosphoribosyl diphosphate (PRPP) synthetase superactivity due to deficiency to this enzyme might be a limiting factor for the effectiveness of this drug in these types of patients.

Keywords: Favipiravir; SARS-CoV-2; Covid-19; Pathopgysiology.

Copyright @ 2020: This is an open-access article distributed under the terms of the Creative Commons Attribution license which permits unrestricted use, distribution, and reproduction in any medium for non-commercial use (NonCommercial, or CC-BY-NC) provided the original author and source are credited.

Favipiravir (FPV, also called avigan, favilavir, favipira, T-705), a pyrazinecarboxamide derivative was discovered by chemical modification of a pyrazine analog [1]. To date, it has been found to act against a number of viruses, including Orthomyxoviridae (Influenza: e.g., seasonal, H5N1, H1N1 pdm09, H7N9, A, B and C), Bunyaviridae (e.g., La Crosse, Punta Toro, Rift Valley fever, Sandfly fever, Dobrava, Maporal, Crimean-Congo hemorrhagic fever, Prospect Hill, and Severe fever thrombocytopenia syndrome), Arenaviridae (e.g., Junin, Pichinde, Tacaribe, Guanarito, Machupo, and Lassa), Filoviridae (e.g., Ebola), Rhabdoviridae (e.g., Rabies), Paramyxoviridae (e.g., Human metapneumovirus, Respiratory syncytial virus), Flaviviridae (e.g., West Nile, Yellow fever, and Zika virus), Togaviridae (e.g., Western equine encephalitis, Venezuelan equine encephalitis, Eastern equine encephalitis, Barmah forest, Ross river, Mayaro, and Chikungunya), Picornaviridae (e.g., Polio, Rhino, and Enterovirus 71) and Caliciviridae (e.g., Noro) [2]. But, there is no record for its anti-coronavirus activity. Recent evidence suggests that this drug may act against life-threatening RNA virus infections [27]. And finally, it undergoes a number of clinical trials with the aim of coronavirus disease 2019 (Covid-19) treatment.
The exact mechanism of interaction of FPV ribofuranosyl-5'-triphosphate (FPV-RTP) with RNAdependent RNA polymerase ( $\mathrm{RdRp}$ ) molecule is yet to be elucidated. It is hypothesized that FPV has virucidal effects, and it may be misincorporated in a nascent viral RNA, or it may act by binding to conserved polymerase domains, thus preventing incorporation of nucleotides for viral RNA replication and transcription [3]. It is demonstrated that FPV induced lethal mutagenic effect on influenza virus [1]. It is a prodrug that is metabolized to its active form, FPV-RTP [4]. Unlike an RNA virus, humans do not have RdRp, but have DNAdependent RNA polymerase (DdRp) and DNAdependent DNA polymerase (DdDp) [3].

In a study, FPV-RTP slightly inhibited human RNA polymerase II, which belongs to DdRp [4]. Human hypoxanthine guanine phosphoribosyltransferase (HPRT) is believed to play a key role in its activation process [4]. HPRT is an enzyme encoded in humans by the hprtl gene, that catalyzes conversion of hypoxanthine to inosine monophosphate and guanine to guanosine monophosphate [5]. This reaction transfers the 5phosphoribosyl group from 5-phosphoribosyl 1pyrophosphate to the purine [6], therefore, it plays a key 
role in the generation of purine nucleotides through the purine salvage pathway [7]. HPRT deficiency is inherited as a recessive X-linked trait [8], thus, males are generally affected and women are the asymptomatic carriers to its deficiency. Partial deficiency of the HPRT is also called Kelley-Seegmiller syndrome (a rare genetic disorder manifesting as a gout-urolithiasis) [9].

The phosphoribosylpyrophosphate synthetase (PRPS) superactivity, a rare X-linked disorder resulting in increased activity of PRPS1, which is the gateway enzyme for the entrance of ribose into the purine pathway, catalyzing the conversion of adenosine triphosphate (ATP) and ribose-5-phosphate to 5phospho- $\alpha$-D-ribosyl, 1-pyrophosphate. PRPS 1 superactivity results in increased purine production, leading to increased urate production and gout. It may also increase the function of mutated proteins [10]. HPRT deficiency and PRPS superactivity in cultured fibroblasts exhibited acceleration of purine synthesis $d e$ novo [11]. It seems HPRT deficiency may be linked to the PRPS superactivity.

In a study, HPRT enzyme has been seen to increase in non-small-cell lung cancer A549 and NCIH460 cells [12]. Rosenstraus and Chasin [13] found that the genes responsible for glucose-6-phosphate dehydrogenase (G6PD) and HPRT activity are linked in Chinese hamster ovary cells. Pai et al., [14] also demonstrated a similar findings in human. G6PD deficiency occurs by $g 6 p d$ gene mutation, is also inherited in an X-linked recessive manner and the most common medical problem include- hemolytic anemia, jaundice, dark urine, fatigue, shortness of breath, rapid heart rate, and so on [15].

Lesch-Nyhan syndrome (LNS) is a rare inherited disorder caused by a deficiency of the HPRT [16]. It is due to mutations in the hprtl gene on the $\mathrm{X}$ chromosome [17]. The HPRT deficiency increases uric acid in our body fluids [18]. Generally, the combination of increased synthesis and decreased utilization of purines leads to high levels of uric acid production results severe gout and kidney problems, poor muscle control and moderate intellectual disability (e.g., selfmutilating behaviors, characterized by lip and finger biting), facial grimacing, involuntary writhing, and repetitive movements of the arms and legs similar to those seen in Huntington's disease [19]. It also causes neurologic and behavioral abnormalities, including mental retardation, spasticity, and choreoathetosis [18]. LNS may exhibit minor neurologic manifestations, including dysarthria, hyperreflexia, positive Babinski's signs, or abnormalities of spinocerebellar function [20]. The cause of the neurological abnormalities may be linked to the poor utilization of vitamin $\mathrm{B}_{12}$ (some males may develop megaloblastic anemia) due to the deficiency of this enzyme [21]. The gene mutation in LNS occurs usually in the mother and passed on to her son (X-linked recessive manner). However, $33 \%$ of all cases arise de novo (from new mutations) and do not have a family history. It should be mentioned that the LNS is present at birth in baby boys (http://ghr.nlm.nih.gov/condition/lesch-nyhan-

syndrome) [22]. Its deficiency has been found to link with myocardial ischemia [23] and hyperuricemia, juvenile-onset gouty arthritis, nephrolithiasis, and mild neurologic symptoms [24].

Moreover, the effectiveness of FPV against influenza pandemics is still controversial [25], as it may develop resistance against influenza virus [26]. Therefore, the effectiveness of this hopeful drug of the patients having a hprtl gene mutation or deficiency of HPRT enzyme, especially who have Kelley-Seegmiller syndrome, Lesch-Nyhan syndrome, myocardial ischemia, hyperuricemia, anemia (e.g., hemolytic and megaloblastic), G6PD deficiency, cardiac diseases, and PRPS superactivity is an important issue. Moreover, FPV has broad-spectrum virucidal as well as genotoxic (on human RNA polymerase II which belongs to DdRp) and mutagenic (on viral cell) effects. Therefore, adequate research is urgently needed regarding the toxicogenetic profile (i.e., toxicity, cytotoxicity, genotoxicity and mutagenicity) to ensure the host genomic safety and stability during the long-term therapy with FPV.

Conflict of interest: None declared.

\section{REFERENCES}

1. Arias, A., Thorne, L., \& Goodfellow, I. (2014). Favipiravir elicits antiviral mutagenesis during virus replication in vivo. Elife, 3, e03679.

2. Furuta, Y., Komeno, T., \& Nakamura, T. (2017). Favipiravir (T-705), a broad spectrum inhibitor of viral RNA polymerase. Proceedings of the Japan Academy, Series B, 93(7), 449-463.

3. Furuta, Y., Takahashi, K., Kuno-Maekawa, M., Sangawa, H., Uehara, S., Kozaki, K., ... \& Shiraki, K. (2005). Mechanism of action of T-705 against influenza virus. Antimicrobial agents and chemotherapy, 49(3), 981-986.

4. Naesens, L., Guddat, L. W., Keough, D. T., van Kuilenburg, A. B., Meijer, J., Voorde, J. V., \& Balzarini, J. (2013). Role of human hypoxanthine guanine phosphoribosyltransferase in activation of the antiviral agent T-705 (favipiravir). Molecular pharmacology, 84(4), 615-629.

5. Ansari, M. Y., Dikhit, M. R., Sahoo, G. C., \& Das, P. (2012). Comparative modeling of HGPRT enzyme of L. donovani and binding affinities of different analogs of GMP. International journal of biological macromolecules, 50(3), 637-649.

6. Guedj, J., Piorkowski, G., Jacquot, F., Madelain, V., Nguyen, T. H. T., Rodallec, A., ... \& De Lamballerie, X. (2018). Antiviral efficacy of favipiravir against Ebola virus: A translational study in cynomolgus macaques. PLoS medicine, 15(3), e1002535.

7. Dudzinska, W., Suska, M., Lubkowska, A., Jakubowska, K., Olszewska, M., Safranow, K., \& Chlubek, D. (2018). Comparison of human 
erythrocyte purine nucleotide metabolism and blood purine and pyrimidine degradation product concentrations before and after acute exercise in trained and sedentary subjects. The Journal of Physiological Sciences, 68(3), 293-305.

8. Hoefnagel, D., Andrew, E. D., Mireault, N. G., \& Berndt, W. O. (1965). Hereditary choreoathetosis, self-mutilation and hyperuricemia in young males. New England Journal of Medicine, 273(3), 130-135.

9. Rodionovskaya, S. R., Zokirov, N. Z., Fedorov, E. S., Tsymbal, I. N., Salugina, S. O., \& Eliseev, M. S. (2011). Description Kelley-Seegmiller syndrome (partial HPRT deficiency manifesting as a gouturolithiasis syndrome) in a patient of 15 years old. Pediatric Rheumatology, 9(S1), P33.

10. Zikánová, M., Wahezi, D., Hay, A., Stibůrková, B. Pitts III, C., Mušálková, D., ... \& Živná, M. (2018). Clinical manifestations and molecular aspects of phosphoribosylpyrophosphate synthetase superactivity in females. Rheumatology, 57(7), 11801185.

11. Zoref-Shani, E., \& Sperling, O. (1980). Characterization of purine nucleotide metabolism in cultured fibroblasts with deficiency of hypoxanthineguanine phosphoribosyltransferase and with superactivity of phosphoribosylpyrophosphate synthetase. Enzyme, 25, 413-418.

12. Townsend, M. H., Anderson, M. D., Weagel, E. G., Velazquez, E. J., Weber, K. S., Robison, R. A., \& O'Neill, K. L. (2017). Non-small-cell lung cancer cell lines A549 and NCI-H460 express hypoxanthine guanine phosphoribosyltransferase on the plasma membrane. OncoTargets and therapy, 10, 1921.

13. Rosenstraus, M., \& Chasin, L. A. (1975). Isolation of mammalian cell mutants deficient in glucose-6phosphate dehydrogenase activity: linkage to hypoxanthine phosphoribosyl transferase. Proceedings of the National Academy of Sciences, 72(2), 493-497.

14. Pai, G. S., Sprenkle, J. A., Do, T. T., Mareni, C. E., \& Migeon, B. R. (1980). Localization of loci for hypoxanthine phosphoribosyltransferase and glucose-6-phosphate dehydrogenase and biochemical evidence of nonrandom $\mathrm{X}$ chromosome expression from studies of a human X-autosome translocation. Proceedings of the National Academy of Sciences, 77(5), 2810-2813.

15. Gersten, T. (2016). Glucose-6-phosphate deficiency. MedlinePlus. February 1; http://www.nlm.nih.gov/medlineplus/ency/article/00 0528.htm.

16. Schretlen, D. J., Callon, W., Ward, R. E., Fu, R., Ho, T., Gordon, B., ... \& Jinnah, H. A. (2016). Do clinical features of Lesch-Nyhan disease correlate more closely with hypoxanthine or guanine recycling?.Journal of inherited metabolic disease, 39(1), 85-91.
17. Shields, L. B., Peppas, D. S., \& Rosenberg, E. (2018). Xanthine calculi in a patient with LeschNyhan syndrome and factor $\mathrm{V}$ Leiden treated with allopurinol: case report. BMC pediatrics, 18(1), 231.

18. Kelley, W. N., Rosenbloom, F. M., Henderson, J. F., \& Seegmiller, J. E. (1967). A specific enzyme defect in gout associated with overproduction of uric acid. Proceedings of the National Academy of Sciences of the United States of America, 57(6), 1735.

19. Schroeder, S. R., Oster- Granite, M. L., Berkson, G., Bodfish, J. W., Breese, G. R., Cataldo, M. F., ... \& Harris, J. C. (2001). Self- injurious behavior: Genebrain-behavior relationships. Mental retardation and developmental disabilities research reviews, 7(1), 312.

20. Kelley, W. N., \& Wyngaarden, J. B. (1983). Clinical syndromes associated with hypoxanthine-guanine phosphoribosyltransferase deficiency. In: Stanbury, J. B., Wyngaarden, J. B., Fredrickson, D. S., Goldstein, J. L., \& Brown, M. S. (ed) Metabolic Basis of Inherited Diseases, $5^{\text {th }}$ edn. McGraw-Hill, 1115-43.

21. Van Der Zee, S. P. M., Schretlen, E. D. A. M., \& Monnens, L. A. H. (1968). Megaloblastic anaemia in the Lesch-Nyhan syndrome. The Lancet, 291(7557), 1427.

22. Lesch-Nyhan syndrome. Genetics Home Reference. February, 2013 http://ghr.nlm.nih.gov/condition/lesch-nyhansyndrome.

23. Wu, J., Bond, C., Chen, P., Chen, M., Li, Y., Shohet, R. V., \& Wright, G. (2015). HIF-1 $\alpha$ in the heart: remodeling nucleotide metabolism. Journal of molecular and cellular cardiology, 82, 194-200.

24. Ea, H. K., Bardin, T., Jinnah, H. A., Aral, B., Lioté, F., \& Ceballos- Picot, I. (2009). Severe gouty arthritis and mild neurologic symptoms due to F199C, a newly identified variant of the hypoxanthine guanine phosphoribosyltransferase. Arthritis \& Rheumatism: Official Journal of the American College of Rheumatology, 60(7), 2201-2204.

25. Tarbet, E. B., Maekawa, M., Furuta, Y., Babu, Y. S., Morrey, J. D., \& Smee, D. F. (2012). Combinations of favipiravir and peramivir for the treatment of pandemic influenza A/California/04/2009 (H1N1) virus infections in mice. Antiviral research, 94(1), 103-110.

26. Goldhill, D. H., Te Velthuis, A. J., Fletcher, R. A., Langat, P., Zambon, M., Lackenby, A., \& Barclay, W. S. (2018). The mechanism of resistance to favipiravir in influenza. Proceedings of the National Academy of Sciences, 115(45), 11613-11618.

27. Shiraki, K., \& Daikoku, T. (2020). Favipiravir, an anti-influenza drug against life-threatening RNA virus infections. Pharmacol Ther. 209:107512. 